\title{
Mental health risk factors for suicides in the US Army, 2007-8
}

\author{
Kathleen E Bachynski, ${ }^{1}$ Michelle Canham-Chervak, ${ }^{1}$ Sandra A Black, ${ }^{2}$ \\ Esther 0 Dada, ${ }^{1}$ Amy M Millikan, ${ }^{2}$ Bruce $\mathrm{H}$ Jones ${ }^{1}$
}

${ }^{1}$ Injury Prevention Program, US Army Public Health Command, Aberdeen Proving Ground, Maryland, USA

${ }^{2}$ Behavioral and Social Health Outcomes Program, US Army Public Health Command, Aberdeen Proving Ground, Maryland, USA

\section{Correspondence to} Dr Michelle Canham-Chervak, US Army Public Health Command, Injury Prevention Program, ATTN: MCHB-IP-DI, Aberdeen Proving Ground, MD 21010-5403, USA; michelle. chervak@us.army.mil

Previous presentation: Force Health Protection Conference, Phoenix, AZ, 7-13 August 2010

Accepted 17 January 2012

Published Online First 8 March 2012

\section{ABSTRACT}

Objective Suicides among active duty US Army personnel have been increasing since 2004, surpassing comparable civilian rates in 2008. This analysis uses US military data to assess suicide rates for the 2-year period 2007-8, and examines relative risks (RR) of suicide associated with mental health disorders.

Methods Historical trends of US Army suicides were assessed using 1977-2008 data from Army G-1 (Personnel). Suicide rates, RR and the 2000-8 trends of mental health disorders were calculated using data from the Defense Casualty Information Processing System and Defense Medical Surveillance System.

Results A total of 255 soldiers committed suicide in 2007-8 (2008 rate 20.2 per 100000 ). Factors associated with higher suicide risk included male gender, lower enlisted rank and mental health disorders treated on an outpatient basis (RR 3.9), as well as a number of mental health disorders (mood disorders, anxiety disorders, posttraumatic stress disorder, personality/psychotic disorders, substance-related disorders and adjustment disorder; RR range 4.7-24.5). Analysis of historical trends suggested that $25-50 \%$ of the suicides that occurred in 2008 might have been related to the major commitment of troops to combat beginning in 2003 .

Conclusions The recent increase in suicides parallels an increase in the prevalence of mental disorders across the army. This finding suggests that increasing rates of clinically treated psychopathology are associated with increasing rates of suicides; these rates probably serve as sentinels for suicide risk in this population. Soldiers seeking treatment for mental disorders and substance abuse should be a focus for suicide prevention.

Suicides among US Army personnel have risen steadily since $2004 .{ }^{1}$ Historically, suicide has been reported as one of the leading causes of death in the US military, ${ }^{2}{ }^{3}$ although military suicide rates have been lower than rates of comparable non-military populations. ${ }^{4}$ Military suicide rates, however, are now surpassing those among comparable civilian populations. In 2008, estimates of the rate of suicide among active duty soldiers in the regular army, army reserve and army national guard began surpassing the suicide rate among US civilians with similar demographics. ${ }^{1} 5$ Whereas civilian rates adjusted to the gender structure of the US Army (younger age and higher percentage male) have remained approximately 18 per 100000 , army rates have increased to over 20 per $100000 .^{5-7}$ In order to address this emerging public health problem, modifiable risk factors for suicide must be identified. Further understanding of the epidemiology of suicide and associated risk factors in the army would facilitate prevention and reduction efforts.

Suicide is complex and multifactorial, with a host of potential and interacting risk factors that have been examined in both the civilian and military literature. Of these, mental health disorders are among the most consistently reported and extensively researched, ${ }^{8-12}$ and may be of particular relevance to the recent increase in suicide rates in the US Army. Individuals with major depressive disorder and bipolar disorder are highly vulnerable to suicidal behaviour; in more than half of all suicides, depression has been shown to be a significant risk factor. ${ }^{13} 14$ Anxiety disorders, psychotic disorders, as well as alcohol and illicit drug abuse, have been found to be associated with suicides, as have personality disorders, particularly schizoid, borderline and narcissistic disorders. ${ }^{15-22}$ Adjustment disorder and post-traumatic stress disorder (PTSD) are frequent mental health diagnoses among military personnel that have been associated with suicide. ${ }^{23-26}$ The risk of suicide is particularly elevated in the presence of comorbid mental and behavioural health disorders. ${ }^{10} 27$

The purpose of this analysis is to use Department of Defense (DoD) administrative and medical surveillance data to provide a preliminary epidemiological assessment of the association of mental disorders with suicide during the years 2007-8. This observational analysis is intended to generate hypotheses and promote further study of the public health problem of suicide in the US military. In addition, this paper documents historical trends (years 1977-2008) in the rates of suicide and recent trends (years 2000-8) in the rates of mental illness among soldiers in the US Army. A final objective was to assess changes in suicide rates that might be associated with involvement in large combat operations.

\section{METHODS}

\section{Data sources}

The data for this analysis came from the Army Behavioural Health Integrated Data Environment, which was established in 2009 by the US Army Public Health Command Behavioural and Social Health Outcomes Programme. This suicide registry consolidates army suicide data from sources including the Defense Casualty Information Processing System, the Department of Defense Manpower Data Center, and the Defense Medical Surveillance System, ${ }^{28}$ an administrative database that captures and maintains information relevant to clinical encounters, including diagnoses from medical providers at the time treatment is received. 
Analyses were restricted to suicides that occurred among soldiers on active duty in the US Army during 2007 and 2008 (the most recent 2-year period for which complete data were available at the time it was obtained in August 2009). Medical data were available only for soldiers on active duty (as it is maintained in active DoD administrative databases); US Army National Guard and Reserve soldiers typically do not serve full time and do not receive most of their medical care in military treatment facilities. Data for suicides included demographics, deployment history and mental health disorders that were diagnosed and treated in military medical facilities or paid for by the military health system. These data were initially obtained in August $2009^{29}$ and were updated in June 2010. Potential cases of suicide were first identified in the Defense Casualty Information Processing System. If confirmed as suicides by the Armed Forces Medical Examiner's Office, they were included as suicide cases in this analysis. Medical encounter measures, including mental health diagnoses, reflect the time period from entry into service to the time of death, discharge from service, or end of the study period (December 2008). The total number of soldiers who had ever deployed versus never deployed was obtained from the Armed Forces Health Surveillance Center.

Comparable data for denominator and risk factors for the army as a whole were obtained from the Defence Medical Epidemiology Database, a web-based application that provides remote access to data contained within the Defense Medical Surveillance System via user-defined queries. ${ }^{30}$ All queries took place in August 2009 and were restricted to active duty army personnel from 2007 to 2008. Ninety four per cent of medical encounters for mental health disorders were ambulatory visits, and most $(76 \%)$ soldiers who were hospitalised for a mental health disorder had the same or a similar diagnosis on one or more outpatient visits before their hospitalisation. Ambulatory data were thus used for the calculation of rates and relative rates of suicide risk associated with specific mental health disorder categories. Results reflect mental disorders diagnosed from January 2007 to December 2008 and were restricted to primary diagnosis and first occurrence per person only. Secondary diagnoses and comorbid mental disorders were not included due to the inability to ascertain the onset and timing of diagnoses from the administrative data.

In addition, US Army rates of suicide during the years 1977-2008 were obtained from US Army G-1 (Personnel) in October 2009 in order to assess historic trends. The proportion of suicides in 2008 that may be attributed to post-2003 events (ie, attributable risk) was estimated by comparing the expected rate of suicide in 2008 (based on previous years) with the actual rate of suicide in 2008.

\section{Measures}

Demographic characteristics included gender, age, race/ethnicity and marital status. Age was divided into three categories: 18-24, 25-34 and 35 years or older. Race/ethnicity included Caucasian, African-American and other (eg, Native American, Asian/Pacific Islander and Hispanic). Marital status was categorised into single, married and other (which, due to small numbers, includes separated, divorced and widowed). Military rank was categorised into lower enlisted (E1-E4), senior enlisted (E5-E9) and officers. Deployment history included 'ever' or 'never' deployed to combat. Mental health diagnoses were categorised as ever or never diagnosed, and were grouped into four diagnostic categories: Mood disorders, anxiety disorders, substance-related disorders and other disorders, which included adjustment disorder, personality disorders and psychotic disorders. Deter- mination of disorders was based on International Classification of Disease, version 9, clinical modification (ICD-9-CM) codes $^{31}$ recorded in the administrative datasets and the Defense Medical Surveillance System. These groupings were adapted from the mental health and substance abuse clinical classifications developed by the Agency for Healthcare Research and Quality. ${ }^{32}$ Table 1 shows the diagnostic categories and specific mental health disorders that were assessed, as well as the ICD-9-CM codes associated with each specific disorder.

\section{Data analysis}

Descriptive statistics on demographic and mental health risk factors and the relative burden of suicide and mental health disorders in the US Army (rates and counts) for 2007 and 2008 were assessed and compared using relative risks (RR) and 95\% confidence interval (CI). In order to assess changes in suicide rates that coincided with increased involvement in large combat operations, we used a linear regression of suicide data from 1977 to 2003 (the point when the major commitment of US troops to the Iraq war started) to project the expected rate of suicides for 2008. The observed 2008 rate was compared with the estimated rate to estimate 'attributable risk' for that year. The equation for 'percent attributable risk' is (rate in exposed)-(rate in unexposed)/(rate in exposed), where 'unexposed' represents the expected suicide rate given peacetime conditions and 'exposed' is the actual suicide rate among army soldiers following major deployment to combat operations. ${ }^{33}$ Due to small sample sizes, data for both years were combined to assess risk factors for suicide deaths among active duty army personnel. Chi-square tests and relative rates of suicide were calculated for each category and compared across groups. Two-by-two tables were constructed using Defense Casualty Information Processing System data to identify suicide cases (numerators) and Defense Medical Surveillance System data to identify non-suicide cases (denominators) to calculate RR. Rates, RR and 95\% CI were validated using the online calculator for comparing person-time rates available at: http://www.openepi.com. ${ }^{34}$ Statistical significance was set at $\alpha=0.05$. While rates based on counts smaller than 20 are generally considered statistically unreliable, ${ }^{35} 36$ they are reported as initial estimates and for subsequent hypothesis generation. Rates and RR are not reported for cell sizes less than five.

Table 1 Categorisation of mental/behavioral health diagnoses by ICD9-CM codes

\begin{tabular}{lll}
\hline $\begin{array}{l}\text { Mental health } \\
\text { diagnostic } \\
\text { categories }\end{array}$ & $\begin{array}{l}\text { Specific mental } \\
\text { health disorders }\end{array}$ & ICD-9-CM code(s) \\
\hline Mood disorders & Major depression & $296.2,296.3$ \\
& Bipolar & $296.0,296.4-296.7,296.80,296.89$ \\
& Dysthymia & 300.4 \\
& Other depression & 311 \\
Anxiety disorders & Non-PTSD anxiety & $300.00,300.02,300.09,300.10$, \\
& disorder & $300.20,300.22,300.23,300.29$, \\
& PTSD & $300.3,308$ \\
Additional mental & Adjustment disorder & 309.81 \\
health disorders & Personality disorder & 301 (except 309.81) \\
Substance related & Psychotic disorder & $295,297,298,300.5$ \\
disorders & Alcohol-related disorder & $291,303,305.0$ \\
& Drug-related disorder & 292 (except 292.2), 304, 305 \\
& & (except 305.0 and 305.1)
\end{tabular}

ICD-9-CM, International Classification of Disease, version 9, clinical modification; PTSD, post-traumatic stress disorder. 


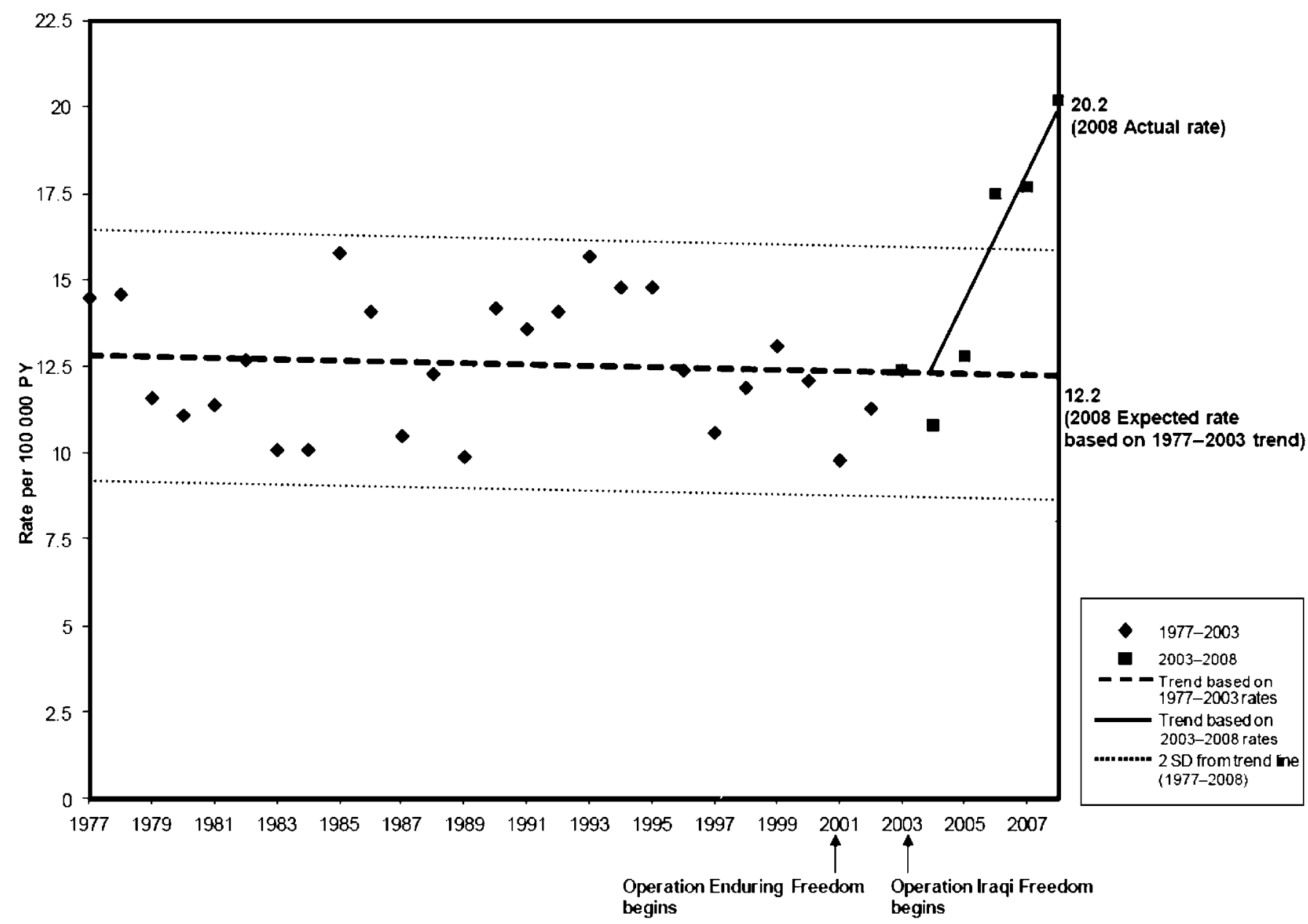

Figure 1 Active duty US Army suicide rates, 1977-2008. Data source: US Army G-1.

\section{RESULTS}

Trend and burden of suicide and mental health disorders

US Army suicide rates nearly doubled from 2004 to 2008, in contrast to the previous slightly downward trend observed since 1977. Figure 1 highlights these trends and compares actual 2004-8 rates of suicide among active duty soldiers with projected 2004-8 rates. Projected rates were based on the assumption that the declining trend of recorded suicide rates observed for the years 1977-2003 would have continued to 2008. The trend line based on 1977-2003 suicide rates and projected to 2008 shows a slightly decreasing trend among the active duty army, whereas the trend line based on actual suicide rates for the years 2004-8 shows an increasing trend. Lines 2 standard deviations (SD) above and below the 1977-2008 trend line provide further statistical context for the temporal variation in suicide rates. Over the 27-year period from 1977 to 2003, no points fell beyond 2 SD of the expected trend. In the following 5-year period (2004-8), however, the rates for 2006, 2007 and 2008 were more than 2 $\mathrm{SD}$ above the expected range.

Comparing the actual 2008 suicide rate $(20.2$ per 100000 person-years) with the expected 2008 suicide rate $(12.2$ per 100000 person-years) results in an attributable proportion of 0.39 (95\% CI 0.27 to 0.52 ). This suggests that an estimated 39\% of suicides that occurred in 2008 may be associated with post2003 military events. The 95\% CI around the point estimate gives an estimated range of $27-52 \%$ of deaths by suicide associated with post-2003 military events.
In relation to mental health disorders, the combined rates of ambulatory visits for the disorders examined nearly doubled from 2000 to 2008. This increase was steady and sharpest in the period 2003-8, nearly doubling from a rate of 116 per 1000 in 2003 to 216 per 1000 person-years in 2008. Figure 2 illustrates this trend in rates by the type of mental disorder. A similar trend

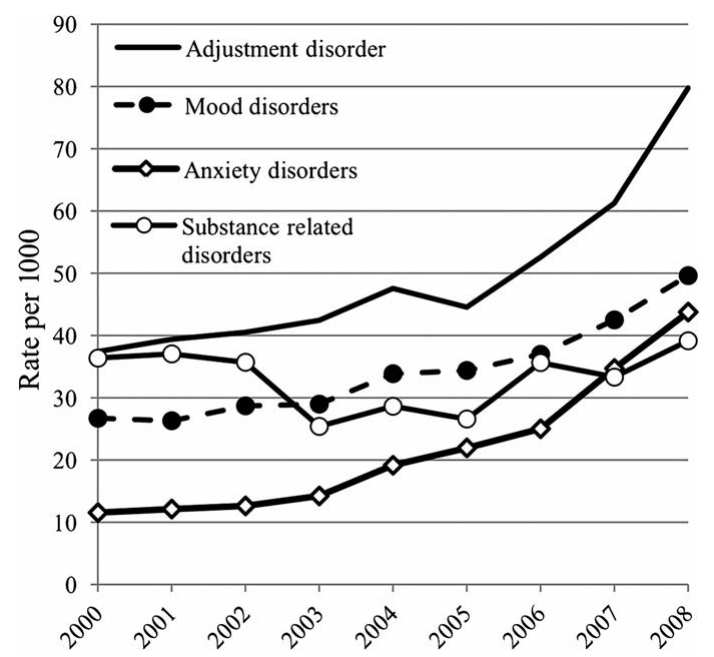

Figure 2 US Army rates of mental health disorders, ambulatory visits 2000-8. Data Source: Defense Medical Surveillance System; diagnoses based on primary diagnosis, first occurrence only. 
was seen in hospitalisations, with an overall increase from 7.4 per 1000 in 2003 to 14.0 per 1000 in 2008.

Demographic characteristics and their associations with suicide A total of 255 active duty soldiers committed suicide in 2007 and 2008 (115 in 2007 and 140 in 2008). Table 2 presents the distribution of demographic characteristics for this group of individuals. Suicides were predominantly male (95\%), $18-24$ years old $(45 \%)$ and Caucasian $(73 \%)$, married at the time of death (59\%) and lower enlisted (54\%). Almost 69\% had been deployed at least once to combat theatre. Table 2 also displays the RR associated with each of the demographic and military characteristics. Male gender was significantly associated with suicide, although it should be noted that the rates are unstable for women due to small numbers. Soldiers aged 25-34 years and African-American individuals were at a significantly lower risk of suicide. The risk of suicide did not differ between soldiers who were married and those who were single. Among the military ranks, the lower enlisted (E1-E4) had a significantly higher rate of suicide than officers. The RR for suicide was higher among those ever deployed compared with those never deployed, but the difference was not statistically significant.

\section{Mental health disorders and their associations with suicide}

Of the 255 suicide cases, $44(17 \%)$ had a previous hospitalisation from January 2007 to December 2008, and 128 (50\%) had a previous ambulatory visit for a mental health disorder during this period. Those with a hospitalisation for a mental disorder were 15.5 (95\% CI 11.2 to 21.5 ) times more likely to commit suicide compared with those who were not hospitalised for any mental health disorder during this time period. Those with an ambulatory visit for a mental disorder were 3.9 (95\% CI 3.0 to 4.9) times more likely to commit suicide compared with those who did not have an ambulatory visit for a mental health disorder during this time period.
Table 3 shows the distribution and RR of suicide associated with specific mental health disorders for 2007-8 combined. It should be noted that an individual could have more than one diagnosis of a mental disorder. All the selected mental disorders were significantly associated with death from suicide $\left(\chi^{2} p\right.$ value $<0.001)$. Among the mood disorders, the RR for suicide among those with an ambulatory visit for dysthymia was 11.5 (95\% CI 7.0 to 18.8$), 6.5$ (95\% CI 4.1 to 10.1) for major depression, 5.5 (95\% CI 2.4 to 12.3 ) for bipolar disorder, and 7.8 (95\% CI 5.6 to 11.1) for other depressive disorders, in comparison with soldiers who did not have such diagnoses.

Among the anxiety disorders, soldiers with anxiety disorders other than PTSD had a RR for suicide of 10.1 (95\% CI 7.4 to 13.8); those with PTSD had a RR of 5.6 (95\% CI 3.6 to 8.7$)$. Of the substance-related disorders, alcohol-related disorders had the strongest association with suicide (RR 7.6; 95\% CI 5.4 to 10.6), followed by drug-related disorders (RR 6.1; 95\% CI 3.7 to 10.0). The RR for suicide among those with personality disorders, psychotic disorders and adjustment disorder were also significant in comparison with soldiers without these diagnoses. It should be noted that rates for counts less than 20 are unstable; these rates should be interpreted with caution.

\section{DISCUSSION}

This paper primarily examines the association of mental health risk factors with suicide among soldiers in the US Army. Mental health disorders, which are among the most consistently reported risk factors for suicide, ${ }^{8} 10$ have been shown to contribute to morbidity among active duty US military personnel. ${ }^{37}$ Rates of suicide in the US Army increased more than $80 \%$ from 2004 to 2008 . They thereby surpassed comparable civilian rates of suicide, which remained relatively stable during this time period. This increase, unprecedented in over 30 years of US Army records, suggests that approximately $40 \%$

Table 2 Demographic and military characteristics of active duty US Army suicides, 2007-8 combined*

\begin{tabular}{|c|c|c|c|c|c|c|}
\hline Characteristic & $\begin{array}{l}\text { No of suicides } \\
(\mathrm{n}=\mathbf{2 5 5})\end{array}$ & $\begin{array}{l}\% \text { of } \\
\text { suicides }\end{array}$ & $\begin{array}{l}\text { Person-years } \dagger \\
(n=1041096)\end{array}$ & $\begin{array}{l}\text { Suicide rate } \\
\text { per } 100000 \\
\text { person-years }\end{array}$ & $\mathbf{R R}$ & (95\% CI) \\
\hline \multicolumn{7}{|l|}{ Gender } \\
\hline Female & 14 & 5.5 & 142111 & 9.9 & 1.0 & (Referent) \\
\hline Male & 241 & 94.5 & 898985 & 26.8 & 2.7 & (1.6 to 4.7 ) \\
\hline \multicolumn{7}{|l|}{ Age group, years } \\
\hline $18-24$ & 114 & 44.7 & 404933 & 28.2 & 1.0 & (Referent) \\
\hline $25-34$ & 73 & 28.6 & 393400 & 18.6 & 0.7 & (0.5 to 0.9 ) \\
\hline $35+$ & 68 & 26.7 & 239437 & 28.4 & 1.0 & (0.7 to 1.4 ) \\
\hline \multicolumn{7}{|l|}{ Race/ethnicity } \\
\hline Caucasian & 186 & 72.9 & 713931 & 26.1 & 1.0 & (Referent) \\
\hline African American & 30 & 11.8 & 212377 & 14.1 & 0.5 & (0.4 to 0.8 ) \\
\hline Other & 39 & 15.3 & 114786 & 34.0 & 1.3 & (0.9 to 1.8 ) \\
\hline \multicolumn{7}{|l|}{ Marital status } \\
\hline Single & 100 & 39.2 & 401454 & 24.9 & 1.0 & (Referent) \\
\hline Married & 151 & 59.2 & 582636 & 25.9 & 1.0 & (0.8 to 1.4 ) \\
\hline Other $\ddagger$ & 4 & 1.6 & 55874 & - & - & - \\
\hline \multicolumn{7}{|l|}{ Rank } \\
\hline Lower enlisted & 137 & 53.7 & 470714 & 29.1 & 1.8 & (1.2 to 2.7 ) \\
\hline Senior enlisted & 90 & 35.3 & 399380 & 22.5 & 1.4 & (0.9 to 2.1 ) \\
\hline Officer & 28 & 11.0 & 171001 & 16.4 & 1.0 & (Referent) \\
\hline \multicolumn{7}{|l|}{ Deployment } \\
\hline Never deployed & 80 & 31.4 & 387710 & 20.6 & 1.0 & (Referent) \\
\hline Ever deployed & 175 & 68.6 & 654099 & 27.4 & 1.3 & (1.0 to 1.7 ) \\
\hline
\end{tabular}

*Data sources: Defense Casualty Information Processing System, Defense Medical Surveillance System.

†For person-years, totals within categories may be less due to incomplete data.

$\ddagger$ Rates and relative risk for 'other' marital status were not calculated due to cell size smaller than five. 
Table 3 RR of suicide among active duty US Army soldiers, 2007-8 combined*

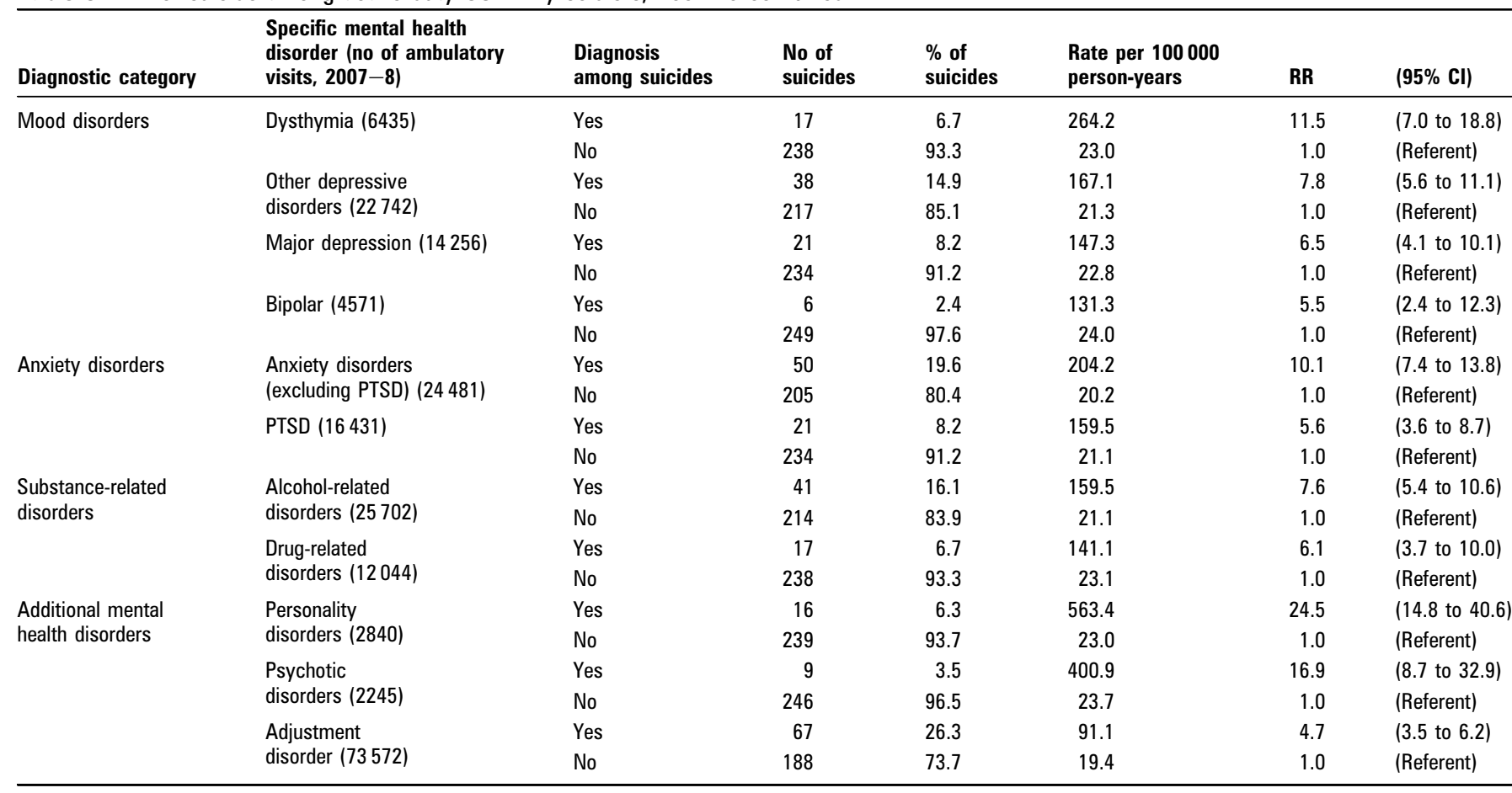

*Data sources: Defense Casualty Information Processing System, Defense Medical Surveillance System.

PTSD, post-traumatic stress disorder.

of suicides that occurred in 2008 may be associated with post2003 events following the major commitment of troops to Iraq in addition to ongoing operations in Afghanistan.

The US Army population is predominantly male, young $(<35$ years old), and Caucasian (see table 2). Consistent with the literature on civilian populations, this study found that male gender, younger age and Caucasian race were associated with higher rates of suicide. ${ }^{10}{ }^{38-40}$ Similar to previous findings in the US military, this study found that lower enlisted personnel have a higher rate of suicide. ${ }^{41}$ No association was found with marital status, potentially because long-term separations and overseas deployment may modify the protective effect of marriage that has been observed in civilian populations. ${ }^{39}{ }^{42-44}$

Suicide rates were higher among soldiers diagnosed with mental illness in the year before their suicide for all mental health disorders examined, findings that are consistent with studies in civilian and military populations. ${ }^{9} 12 \quad 2123 \quad 24 \quad 4546$ Notably, over one quarter of soldiers who committed suicide had a diagnosis of adjustment disorder. Adjustment disorder, a relatively short-term diagnosis occurring in close proximity to stressful events, may be used when a more precise diagnosis has not been identified. ${ }^{47}$ It is especially prevalent among military trainees $^{48-50}$ and in medical evacuation from combat theatre. ${ }^{26}$

The overall rates of mental illness among active duty soldiers also nearly doubled since the major commitment of troops to Iraq and Afghanistan, mirroring the increase in rates of suicide from 2003 to 2008. This suggests a possible association between the increase in mental health disorders and suicide in a population under severe stress. The 2008 rate indicates that more than one fifth of all active duty soldiers had an ambulatory visit for a mental health disorder, implying a prevalent public health problem.

The increase in suicide rates may be viewed as the tip of the 'mental health iceberg'. While suicide remains a relatively rare event, its increase signals more prevalent underlying mental health problems among soldiers in the US Army. The parallel increase in trends of suicide rates and mental health disorders during the years 2003-8 suggests that army operations during this time period may have affected the nature and extent of mental health problems, including suicide. Earlier studies suggest that military deployment may increase the risk of mental disorders and psychosocial distress. ${ }^{51-59}$ Given that current psychosocial stresses are thought to play a predisposing and triggering role in suicidal behaviour, ${ }^{40} 6061$ deployment and potential combat exposure may serve as a source of such stresses. Stress and potential risk factors for suicide, such as extended separations due to deployment and training, exposure to traumatic events in combat, homecoming issues, implications of legal difficulties for eligibility for re-enlistment and promotion, access to firearms, and weapons training may be especially relevant among military personnel. ${ }^{62-64}$ The possibility of combat deployment as an effect modifier amplifying other risk factors should also be considered.

In the present study, $31 \%$ of suicides were committed by soldiers who had never deployed, implying that psychopathology and stress other than combat exposure may contribute to suicide incidence in this population. Predeployment stress, such as anticipatory anxiety and preexisting trauma, may play an important role. ${ }^{6-69}$ Changes in recruitment standards or screening processes before entrance into the army may also be involved. The role of non-combat stress in suicide incidence, as well as the effect of the increased pace of military operations throughout the army, need to be elucidated further. ${ }^{70-72}$

Higher suicide rates among those with diagnosed mental health disorders suggest the importance of suicide prevention strategies, including identification, treatment and monitoring of major risk factors for suicide. Potential existing prevention strategies include: the education of 'gatekeepers' (such as clergy, primary care physicians and first responders) who have contact with populations vulnerable to mental health disorders and suicide; ${ }^{73} 74$ effective treatment of depression and other mental disorders; ${ }^{75}$ and proper gun storage practices. ${ }^{77} 78$ All 
implemented policies, programmes and interventions should undergo ongoing evaluation, including existing army mental health and suicide interventions such as 'Re-Engineering Systems of Primary Care for PTSD and Depression in the Military (RESPECT-mil)', 'Battlemind' and 'Ask, Care, Escort' (ACE).$^{79-83}$ Surveillance of suicides and mental health disorders should continue to be routinely conducted to track trends and to monitor programme and policy effectiveness.

\section{Limitations}

Counts of active duty soldiers with a primary diagnosis of a mental health disorder during 2007 or 2008 were used in risk calculations. Although persons with mental health secondary diagnoses may have been missed, using primary diagnoses provided certainty that the conditions were those for which the patient sought and received treatment. Relative rates may thus be conservative estimates. In most cases, however, the size and statistical strength of the relative rates strongly suggest an association with suicide. An additional limitation concerns the low counts of certain mental health disorders among the suicide cases. Caution must be used in interpreting these results, as such limited numbers result in unstable rate estimates and can easily underestimate or overestimate associations. Limitations of the DoD administrative, common-access databases from which the mental health data were obtained include the aggregated nature of the data, and that individual soldiers may have received assessment and treatment outside of the army medical environment (for which DoD databases would not have a record). For example, analyses do not capture mental health care received through alternative sources such as Military One Source or community health clinics. ${ }^{84}$ The data also do not cover potentially relevant mental health diagnoses and treatment before enlistment in the army. Although the literature suggests that suicide results from multiple risk factors including personal stressors such as relationship, legal and financial problems, ${ }^{41} 85$ this analysis focuses on mental health risk factors only. Furthermore, the study is limited in its ability to assess trends in association of mental health disorders with suicide over time because only associations for the period from 2007 to 2008 were examined. This study also does not assess the association of suicide with suicide attempts and suicide ideations. Finally, given the uniqueness of the military population, the generalisability of these results to other populations is limited.

\section{Strengths}

This analysis offers a preliminary epidemiological assessment of mental health risk factors for suicide among active duty US Army personnel using existing military medical surveillance and suicide report data. The results provide evidence of important mental health risk factors for suicide. Further exploration of these risk factors is needed. A particular strength of the present study was the reliance on data obtained from the Defense Medical Surveillance System, which encompasses all mental health medical encounters among active duty soldiers paid for by the US military health system, including care received in fixed military treatment facilities (ie, not temporary) as well as care received in civilian medical treatment facilities. In addition, suicide cases in the registry were obtained from official DoD and army casualty data sources (Defense Casualty Information Processing System, G1), in which reporting is generally complete. Whereas suicide counts are known to fluctuate slightly as cases are evaluated and re-evaluated, these counts are consistent with cases as defined in June 2010 when the data were obtained.

\section{What is already known on the subject}

Suicide rates have been increasing in the US Army since 2004.

- Mental health disorders are among the most consistently reported risk factors for suicide.

- Epidemiological studies on mental health risk factors that provide measures of association with suicide among military populations remain limited.

\section{What this study adds}

- This study provides a preliminary epidemiological assessment of the association of demographic and mental disorders with suicide in the US Army during 2007-8.

- Mood disorders, adjustment disorder, PTSD and alcoholrelated disorders are prevalent mental health disorders associated with suicide in this population.

\section{CONCLUSIONS}

Army suicide rates have been increasing since 2004, and rates of mental illness, indicators of soldier stress, have also been increasing during this same time period. A number of identifiable mental health risk factors were found to be associated with suicide in the US Army, including mood, anxiety, adjustment, personality, psychotic and substance-related disorders. The associations reported in this study are generally consistent with earlier research, but should be confirmed in studies with a longer time frame and a larger sample size. Future studies should use multivariate analyses to examine the effects of comorbid conditions and the relative contribution of multiple risk factors. Mood disorders, adjustment disorder, PTSD and alcohol-related disorders are of particular concern given their prevalence and strong association with suicide. The recent increase in suicide rates may be viewed as the tip of the 'mental health iceberg', signalling more prevalent underlying mental health problems. Before the increase in suicide rates, there was a slightly decreasing trend of suicide rates among active duty US Army personnel during the years 1977-2003, suggesting that the increase is associated with army operations subsequent to 2003. Further study is needed to define specific factors, both individual and social, which contributed to this increase. As risk factors for stress and mental health disorders, preparation for deployment and potential combat exposure may play an important role in these trends.

Acknowledgements The authors gratefully acknowledge the support for this analysis and thoughtful editing received from Dr Michael R Bell. They also thank the anonymous reviewers for their helpful comments.

Contributors KEB made substantial contributions to the conception and design, acquired, analysed and interpreted the data presented in the manuscript, drafted the article and managed all revisions and production of the final manuscript. MCC made contributions to the conception and design, the analysis and interpretation of results, and provided critical reviews and intellectual input to manuscript drafts. SAB made contributions to the conception and design, assisted with acquisition of the data, and provided critical reviews and intellectual input to manuscript drafts. EOD made contributions to the conception and design, furnished critical analytic support, and provided critical reviews and intellectual input to manuscript drafts. AMM made contributions to the conception and design, the acquisition of data, and provided critical reviews and intellectual input to manuscript drafts. BHJ made substantial contributions to the conception and design, the analysis and interpretation of data, 
and provided critical reviews and intellectual input to manuscript drafts. All authors gave approval to the final version to be published.

Funding This work was supported in part by an appointment to the postgraduate research participation program at the US Army Public Health Command (USAPHC) administered by the Oak Ridge Institute for Science and Education through an interagency agreement between the US Department of Energy and USAPHC.

\section{Competing interests None.}

Provenance and peer review Not commissioned; externally peer reviewed.

Data sharing statement Data for this article were obtained from the Army Behavioral Health Integrated Data Environment (ABHIDE). Requests for these data are handled by the US Army Public Health Command (http://phc.amedd.army.mil/). Data were also obtained from the Defense Medical Epidemiology Database (DMED). Requests for these data are handled by the Armed Forces Health Surveillance Center (http://afhsc.army.mil/).

\section{REFERENCES}

1. Kuehn BM. Soldier suicide rates continue to rise: military, scientists work to stem the tide. JAMA 2009;301:1111-13.

2. Jones BH, Amoroso PJ, Canham ML, et al. Atlas of injuries in the U.S. armed forces. Mil Med 1999;164(8 Suppl):633.

3. Ritchie EC, Keppler WC, Rothberg JM. Suicidal admissions in the United States military. Mil Med 2003;168:177-81.

4. Hill JV, Johnson RC, Barton RA. Suicidal and homicidal soldiers in deployment environments. Mil Med 2006;171:228-32.

5. Levin A. Military brass address suicide crisis and strategies to cure it. Psychiatr News 2009;44:10.

6. Black SA, ed. Brief to the U.S. Army Suicide Reduction And Prevention Research Strategic Planning Workgroup. Fort Detrick, MD: Military Operational Medicine Research Program, 2009.

7. National Center for Injury Prevention and Control. Centers for Disease Control And Prevention (Producer). 2003. http://www.cdc.gov/ncipc/wisqars (accessed 17 Aug 2009).

8. Cavanagh JT, Carson AJ, Sharpe M, et al. Psychological autopsy studies of suicide: a systematic review. Psychol Med 2003;33:395-405.

9. Harris EC, Barraclough B. Suicide as an outcome for mental disorders. A metaanalysis. Br J Psychiatry 1997;170:205-28.

10. Nock MK, Borges G, Bromet EJ, et al. Suicide and suicidal behavior. Epidemiol Rev 2008:30:133-54

11. Hilton SM, Service DB, Stander VA, et al. Department of the Navy Suicide Incident Report (DONSIR): Summary of 1999-2007 Findings. Report no. 09-15. San Diego, CA: Naval Health Research Center, 2009.

12. Mahon MJ, Tobin JP, Cusack DA, et al. Suicide among regular-duty military personnel: a retrospective case-control study of occupation-specific risk factors for workplace suicide. Am J Psychiatry 2005;162:1688-96.

13. Lonnquist JK. Psychiatric aspects of suicidal behaviour: depression. In: Hawton K, van Heerigen K, eds. The International Handbook of Suicide and Attempted Suicide. Chichester: John Wiley \& Sons Ltd, 2000:107-20.

14. Pompili M, Innamorati M, Raja M, et al. Suicide risk in depression and bipolar disorder: do impulsiveness-aggressiveness and pharmacotherapy predict suicidal intent? Neuropsychiatr Dis Treat 2008;4:247-55.

15. Alcohol and suicide among racial/ethnic populations-17 states, 2005-2006. MMWR Morb Mortal Wkly Rep 2009;58:637-41.

16. Allebeck $\mathbf{P}$, Allgulander C, Fisher LD. Predictors of completed suicide in a cohort of 50,465 young men: role of personality and deviant behaviour. BMJ 1988;297:176-8.

17. Allugander C. Psychiatric aspects of suicidal behaviour: anxiety disorders. In: Hawton K, van Heerigen K, eds. The International Handbook of Suicide and Attempted Suicide. Chichester: John Wiley \& Sons Ltd, 2000:179-92.

18. Brown S, Inskip H, Barraclough B. Causes of the excess mortality of schizophrenia. Br J Psychiatry 2000:177:212-17.

19. Conner KR, Cox C, Duberstein PR, et al. Violence, alcohol, and completed suicide: a case-control study. Am J Psychiatry 2001;158:1701-5.

20. de Hert M, Peuskens J. Psychiatric aspects of suicidal behaviour: schizophrenia. In: Hawton K, Van Heerigen K, eds. The International Handbook of Suicide and Attempted Suicide. Chichester: John Wiley \& Sons Ltd, 2000:121-34.

21. Rivara FP, Mueller BA, Somes G, et al. Alcohol and illicit drug abuse and the risk of violent death in the home. JAMA 1997;278:569-75

22. Oquendo MA, Carballo JJ, Stanley B, et al. Personality disorders. In: Simon RIHR, ed. Suicide Assessment and Management. Washington: American Psychiatric Publishing, 2006:329-46.

23. Gradus JL, Qin P, Lincoln AK, et al. The association between adjustment disorder diagnosed at psychiatric treatment facilities and completed suicide. Clin Epidemiol 2010:2:23-8.

24. Gradus $\mathbf{J L}$, Qin $\mathrm{P}$, Lincoln AK, et al. Posttraumatic stress disorder and completed suicide. Am J Epidemiol 2010;171:721-7.

25. Hoge CW, Toboni HE, Messer SC, et al. The occupational burden of mental disorders in the U.S. military: psychiatric hospitalizations, involuntary separations, and disability. Am J Psychiatry 2005;162:585-91.
26. Rundell JR. Demographics of and diagnoses in operation enduring freedom and operation Iraqi freedom personnel who were psychiatrically evacuated from the theater of operations. Gen Hosp Psychiatry 2006;28:352-6.

27. Dumais $\mathbf{A}$, Lesage $A D$, Alda $M$, et al. Risk factors for suicide completion in major depression: a case-control study of impulsive and aggressive behaviors in men. Am J Psychiatry 2005:162:2116-24.

28. Toppings P. Army Behavioral Health Integrated Data Environment. (ABHIDE). In: Notices. Federal Register. Washington, DC: US Government Printing Office, 2009:62765-7.

29. Bachynski KE, Black S, Canham-Chervak M, et al. U.S. Army Suicides, 2007-2008: An Analysis Of Selected Demographic and Mental/Behavioral Health Risk Factors. Epidemiological report no. 12-HF-OBHP-10. Aberdeen Proving Ground, MD: U.S. Army Public Health Command (Prov), 2010.

30. Rubertone MV, Brundage JF. The defense medical surveillance system and the department of defense serum repository: glimpses of the future of public health surveillance. Am J Public Health 2002;92:1900-4.

31. World Health Organization. Manual of the International Statistical Classification of Diseases, Injuries and Causes of Death, 9th Revision. Geneva, Switzerland: World Health Organization, 1977

32. Healthcare Cost and Utilization Project. Mental Health and Substance Abuse Clinical Classifications: Agency for Healthcare Research and Quality. Rockville, MD. http://www.hcup-us.ahrq.gov/toolssoftware/mhsa/mhsa.jsp (accessed 17 Dec 2009)

33. Szklo M, Nieto F. Epidemiology: Beyond the Basics. Gaithersburg, Maryland: Aspen Publishers, 2000.

34. Dean AG, Sullivan KM, Soe MM. OpenEpi: open source epidemiologic statistics for public health, version 2.3. http://www.OpenEpi.com (accessed 1 Dec 2009)

35. Miniño AM, Arias E, Kochanek KD, et al. Deaths: Final Data For 2000. National Vital Statistics Reports National Center for Health Statistics. Hyattsville, Maryland: National Center for Health Statistics, 2002

36. Washington State Department of Health. Guidelines For Working With Small Numbers. 2009. http://www.doh.wa.gov/Data/guidelines/SmallNumbers.htm (accessed 4 Dec 2009).

37. Hoge CW, Lesikar SE, Guevara R, et al. Mental disorders among U.S. military personnel in the 1990s: association with high levels of health care utilization and early military attrition. Am J Psychiatry 2002;159:1576-83.

38. Hawton K. Sex and suicide. Gender differences in suicidal behaviour. Br J Psychiatry 2000;177:484-5

39. Kposowa AJ. Marital status and suicide in the national longitudinal mortality study J Epidemiol Community Health 2000;54:254-61.

40. Mann JJ. A current perspective of suicide and attempted suicide. Ann Intern Med 2002;136:302-11.

41. Rothberg JM, Jones FD. Suicide in the U.S. Army: epidemiological and periodic aspects. Suicide Life Threat Behav 1987:17:119-32.

42. Luoma JB, Pearson JL. Suicide and marital status in the United States, 1991-1996: is widowhood a risk factor? Am J Public Health 2002;92:1518-22.

43. Oin $\mathbf{P}$, Agerbo $E$, Mortensen PB. Suicide risk in relation to socioeconomic, demographic, psychiatric, and familial factors: a national register-based study of al suicides in Denmark, 1981-1997. Am J Psychiatry 2003;160:765-72.

44. Smith JC, Mercy JA, Conn JM. Marital status and the risk of suicide. Am J Public Health 1988;78:78-80.

45. Simon GE, VonKorff M. Suicide mortality among patients treated for depression in an insured population. Am J Epidemiol 1998;147:155-60.

46. Qin $\mathbf{P}$, Nordentoft $M$. Suicide risk in relation to psychiatric hospitalization: evidence based on longitudinal registers. Arch Gen Psychiatry 2005;62:427-32.

47. Casey P. Adult adjustment disorder: a review of its current diagnostic status. $J$ Psychiatr Pract 2001;7:32-40.

48. Koshes RJ, Rothberg JM. Parasuicidal behavior on an active duty army training post. Mil Med 1992;157:350-3.

49. Cigrang JA, Carbone EG, Todd S, et al. Mental health attrition from Air Force basic military training. Mil Med 1998;163:834-8.

50. Englert DR, Hunter CL, Sweeney BJ. Mental health evaluations of U.S. Air Force basic military training and technical training students. Mil Med 2003:168:904-10.

51. Hoge CW, Auchterlonie JL, Milliken CS. Mental health problems, use of mental health services, and attrition from military service after returning from deployment to Iraq or Afghanistan. JAMA 2006:295:1023-32.

52. Tanielian T, Jaycox L, eds. Invisible Wounds of War: Psychological and Cognitive Injuries, Their Consequences, and Services to Assist Recovery: RAND Center for Military Health Policy Research. 2008. http://www.rand.org/pubs/monographs/2008/ RAND_MG720.pdf (accessed 11 Sep 2009).

53. Buydens-Branchey L, Noumair D, Branchey M. Duration and intensity of combat exposure and posttraumatic stress disorder in Vietnam veterans. J Nerv Ment Dis 1990;178:582-7.

54. Jacobson IG, Ryan MA, Hooper TI, et al. Alcohol use and alcohol-related problems before and after military combat deployment. JAMA 2008;300:663-75.

55. Prigerson HG, Maciejewski PK, Rosenheck RA. Population attributable fractions of psychiatric disorders and behavioral outcomes associated with combat exposure among US men. Am J Public Health 2002;92:59-63.

56. Sareen J, Cox BJ, Afifi T0, et al. Combat and peacekeeping operations in relation to prevalence of mental disorders and perceived need for mental health care: findings from a large representative sample of military personnel. Arch Gen Psychiatry 2007:64:843-52.

57. Wojcik BE, Akhtar FZ, Hassell LH. Hospital admissions related to mental disorders in U.S. Army soldiers in Iraq and Afghanistan. Mil Med 2009;174:1010-18. 
58. USACHPPM. Technical Report No. 14-HK-OB1U-09, Investigation of Homicides at Fort Carson, Colorado, November 2008-May 2009. Aberdeen Proving Ground, MD: U.S. Army Center for Health Promotion and Preventive Medicine, 2009.

59. Milliken CS, Auchterlonie JL, Hoge CW. Longitudinal assessment of mental health problems among active and reserve component soldiers returning from the Iraq war. JAMA 2007:298:2141-8.

60. Rihmer Z. Suicide risk in mood disorders. Curr Opin Psychiatry 2007;20:17-22

61. Moscicki EK. Epidemiology of suicidal behavior. Suicide Life Threat Behav 1995;25:22-35

62. Martin J, Ghahramanlou-Holloway M, Lou K, et al. A comparative review of U.S military and civilian suicide behavior: implications for OEF/OIF suicide prevention efforts. J Ment Health Couns 2009:31:101-18.

63. Krysinska K, Lester D, Martin G. Suicidal behavior after a traumatic event. J Trauma Nurs 2009;16:103-10.

64. Jones N, Greenberg N, Fear NT, et al. The operational mental health consequences of deployment to Iraq for UK Forces. J R Army Med Corps 2008;154:102-6.

65. Breslau N, Chilcoat HD, Kessler RC, et al. Previous exposure to trauma and PTSD effects of subsequent trauma: results from the detroit area survey of trauma. Am J Psychiatry 1999:156:902-7.

66. Breslau N, Peterson EL, Schultz LR. A second look at prior trauma and the posttraumatic stress disorder effects of subsequent trauma: a prospective epidemiological study. Arch Gen Psychiatry 2008:65:431-7.

67. MacDonald C, Chamberlain K, Long N, et al. Mental health, physical health, and stressors reported by New Zealand Defence Force peacekeepers: a longitudinal study. Mil Med 1998;163:477-81.

68. Maguen S, Litz BT, Wang JL, et al. The stressors and demands of peacekeeping in Kosovo: predictors of mental health response. Mil Med 2004;169:198-206.

69. Maguen S, Turcotte DM, Peterson AL, et al. Description of risk and resilience factors among military medical personnel before deployment to Iraq. Mil Med 2008;173:1-9.

70. Litz BT. Research on the impact of military trauma: current status and future directions. Mil Psychol 2007;19:217-38.

71. Sudum K, Eyvindoson J. Effects of Personnel Tempo on Military Members, their Families, and the Organization: An Annotated Bibliography. Ottawa: Defense Research and Development Canada, Centre for Operational Research and Analysis, 2008.
72. Rona RJ, Fear NT, Hull L, et al. Mental health consequences of overstretch in the UK armed forces: first phase of a cohort study. BMJ 2007;335:603

73. Luoma JB, Martin CE, Pearson JL. Contact with mental health and primary care providers before suicide: a review of the evidence. Am J Psychiatry 2002;159:909-16.

74. Mann JJ, Apter A, Bertolote J, et al. Suicide prevention strategies: a systematic review. JAMA 2005:294:2064-74

75. Arroll B, Macgillivray S, Ogston S, et al. Efficacy and tolerability of tricyclic antidepressants and SSRls compared with placebo for treatment of depression in primary care: a meta-analysis. Ann Fam Med 2005;3:449-56.

76. Barbui C, Esposito E, Cipriani A. Selective serotonin reuptake inhibitors and risk of suicide: a systematic review of observational studies. Can Med Assoc J 2009;180:291-7

77. Grossman DC, Mueller BA, Riedy C, et al. Gun storage practices and risk of youth suicide and unintentional firearm injuries. JAMA 2005;293:707-14.

78. Shenassa ED, Rogers ML, Spalding KL, et al. Safer storage of firearms at home and risk of suicide: a study of protective factors in a nationally representative sample. $J$ Epidemiol Community Health 2004;58:841-8.

79. Adler AB, Castro CA, McGurk D. Time-driven battlemind psychological debriefing: a group-level early intervention in combat. Mil Med 2009:174:21-8.

80. Engel CC, Oxman T, Yamamoto $\mathrm{C}$, et al. RESPECT-Mil: feasibility of a systems-leve collaborative care approach to depression and post-traumatic stress disorder in military primary care. Mil Med 2008;173:935-40.

81. Kuehn BM. Scientists examine primary care-based screening and treatments for anxiety. JAMA 2008;299:1886-7.

82. Bradford L. Army takes new approach to suicide prevention. Army News Serv 2009 http://www.army.mil/-news/2009/06/12/22576-army-takes-new-approach-to-suicideprevention (accessed 22 0ct 2009)

83. Suicide Prevention Resource Center. Best Practices Registry Section III: Adherence To Standards: Army ACE Suicide Prevention Program. 2010. http://www2. sprc.org/sites/sprc.org/files/ArmyACE.pdf (accessed 19 Feb 2010).

84. Williams R. 'Military one source' helps with family problems. Am Forces Press Serv 2004. http://www.militaryinfo.com/news_story.cfm?textnewsid=1065 laccessed 22 Oct 2009)

85. Phillips MR, Yang G, Zhang Y, et al. Risk factors for suicide in China: a national case-control psychological autopsy study Lancet 2002·360:1728-36.

\section{Deaths in UAE road crashes during Eid}

Eight people were killed in traffic during the Eid Al Fitr holidays. The events included examples of driver negligence and failing to leave a safe distance between vehicles, failure to wear a seat belt, speeding, and not paying attention. azacharias@thenational.ae.

\section{Queensland Trauma registry defunded}

For reasons best known to the politicians, funding for the important Queensland Trauma Registry (QTR) ceased at the end of June 2012. The website lists a large number of OTR achievements: quality assurance in trauma care; data and supporting statistical analysis relevant to trauma policy and practice; regular statistical reports on injury and trauma systems performance; the development and evaluation of the Queensland Trauma Plan; the development and implementation of a Bi-national Trauma Minimum Data Set (Australia and New Zealand); the regular Queensland Trauma Review. http://www.uq.edu.au/conrod/index.html?page=11386 